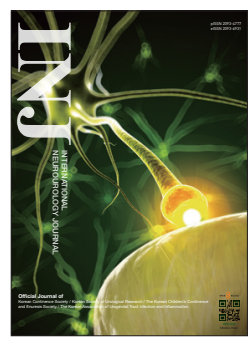

\title{
Translational Research for Pediatric Lower Urinary Tract Dysfunction
}

\author{
Akihiro Kanematsu \\ Department of Urology, Hyogo College of Medicine, Nishinomiya, Japan
}

\begin{abstract}
This review provides a comprehensive view of translational research aimed at elucidating the pathophysiology of pediatric lower urinary tract dysfunction (LUTD). A web search was conducted according to combinations of keywords, and the significance of each article was defined by the author. The dramatic evolution of the mass analysis method of genomes, transcripts, and proteins has enabled a comprehensive analysis of molecular events underlying diseases, and these methodologies have also been applied to pediatric LUTD. In genetic analyses of syndromes underlying daytime incontinence, urofacial (Ochoa) syndrome may be creating a prototype of a new research approach. Nocturnal enuresis has long been studied genetically, and several candidate loci have been reported. However, the pursuit for enuresis genes has been abandoned partly because genetic association and enuresis phenotype (bladder or renal type) could not be linked. Enuresis associated with diabetes insipidus has provided new insights into the etiology of the diseases. A chronobiological approach may shed new light on this area. Posterior urethral valves and neurogenic bladders have attracted the interest of pediatric urologists to the smooth muscle biology of the bladder. Bladder exstrophy and cloacal anomalies are rare but major anomalies caused by defective urorectal development and have recently been studied from a genetic standpoint. Translational studies for pediatric LUTD may be extended to adult bladder disease, or to application of precision medicine for diseased children.
\end{abstract}

Keywords: Pediatrics; Lower Urinary Tract Symptoms; Genomics; Enuresis; Urinary Incontinence

- Conflict of Interest: No potential conflict of interest relevant to this article was reported.

\section{INTRODUCTION}

Pediatric lower urinary tract dysfunction (LUTD) involves a broad spectrum of conditions. Daytime urinary urgency, incontinence, and nocturnal enuresis are documented in 5\%-15\% of school children $[1,2]$, but the majority of them are self-resolving and can be conceived as failure to achieve appropriate coordinated micturition behavior or day-and-night micturition cycles. More severe cases requiring medical care usually involve daytime incontinence and may show detrusor overactivity or impaired sphincter function as an underlying cause. Most severe cases are usually associated with underlying or concomi- tant disorders such as spinal disorders, psychological or cerebral disorders, bladder outlet obstruction, and very rare congenital anomalies including cloacal anomaly, bladder and cloacal exstrophy, and others.

This review covers basic research findings involving pediatric LUTD, with special emphasis on the research findings that recent genomics, proteomics, and cell biology has provided for elucidation of the pathophysiology of these diseases. We excluded research aimed at 'regenerative medicine' including cell therapy, tissue engineering, novel devices, and pharmaceutical therapies, because there have already been many reviews on these topics including our own $[3,4]$.

Corresponding author: Akihiro Kanematsu (iD http://orcid.org/0000-0002-0669-8986 Department of Urology, Hyogo College of Medicine, Mukogawacho, Nishinomiya, Hyogo 663-8501, Japan

E-mail: aqui@hyo-med.ac.jp / Tel: +81-798-45-6366 / Fax: +81-798-45-6368

Submitted: September 24, 2016 / Accepted after revision: October 17, 2016 


\section{METHODS}

A PubMed search was conducted according to a combination of keywords including, 'congenital,' 'pediatric', 'bladder,' 'enuresis, 'incontinence,' 'gene, 'genome,' 'genetics,' 'proteomics,' 'posterior urethral valve' and 'translational,' but NOT 'cancer' or 'neoplasm.' Of them, 'regenerative medicine' reviews were excluded. Those treating pure animal experiments were kept to a minimum, and were limited to those having relevant clinical implications. Retrieved articles considered relevant were classified according to subject topics, and the significance or each article was defined by the author.

\section{RESEARCH METHODOLOGY}

The dramatic evolution of mass analysis methods of genomes, transcripts, and proteins is allowing for comprehensive analysis of molecular events underlying various diseases.

Genomic analysis has been employed to investigate inherited genetic disorders, and is often able to detect causative genetic defects of diseases. Single nucleotide polymorphisms (SNPs) have also been implicated for candidate genes of diseases. Recently, sequencing technology has rapidly advanced in terms of time and cost, making whole genome sequencing (WGS) relatively common. The cost issue is crucial, since funding support required for application of such innovative methods is not easily obtained for relatively minor diseases, like pediatric LUTD. Through the use of this technology, whole genome SNP mapping has become more feasible. Copy number variation (CNV) is a relatively new field. It is defined as a phenomenon in which sections of the genome are repeated and the number of repeats in the genome varies between individuals in the human population [5,6]. Reports utilizing CNV data have been increasing as WGS has become more feasible.

Although genomic variation should entail phenotypic change through transcription to mRNA and translation to protein level, transcriptome is less easy to investigate than genomes, because of ethical and clinical hurdles against obtaining human materials for extracting RNA and protein samples. Application of these new methods to humans requires ethical justification for obtaining samples in a way as least invasive as reasonably achievable. For the same reason, proteomics analysis of human organs is not easily attainable [7]. Pediatric LUTD is functional disease, and except for special circumstances like bladder augmentation [8], pathological specimens are usually not obtained. On the other hand, urine can be readily obtained and urinary proteins may reflect certain pathological conditions in the urinary tract. One major problem is that such proteins may most likely have renal origins, and only a small portion of them may derive from the bladder. For example, groups investigated the expression level of prostaglandin E2 and nerve growth factor (NGF) for overactive bladder $(\mathrm{OAB})$ in children, but in both cases it is difficult to prove whether these molecules are secreted from the bladder or from the kidney [9-11]. Comprehensive proteomics using mass spectrometry has been investigated for upper urinary tract diseases, but not applied to LUTD yet $[12,13]$.

There are also other omics approaches that may have clinical significance for pediatric diseases like microbiomics and metabolomics, although clinical investigation is yet to be done [14].

\section{DISEASE CONDITIONS}

\section{Daytime Incontinence}

Involuntary urination (incontinence) during the daytime is not uncommon in school children, and usually resolves with the age [1]. Since urinary continence is accomplished by a complex coordination of bladder detrusor, urethral sphincter, afferent and efferent innervation, various diseases can be underlying causes. Of those, Ochoa syndrome (urofacial syndrome) has attracted the interest of basic scientists. Since the first report by Ochoa on association between characteristic facial features and urinary incontinence in 1987 [15,16], a genomic analysis reported in 1997 designated the association of a chromosomal region in 10q23-q24 [17], whole genome SNP mapping identified HPSE2 gene coding heparanase-2 and LRIG2 as causative genes $[18,19]$, and recently a model mouse was created [16].

Such an approach may become a research prototype, which can be adopted for other rare diseases having distinct genetic causes. Noonan syndrome [20], Fragile X syndrome [21], or 21 trisomy (Down syndrome) [22] can all be causes for daytime urinary incontinence. Association of these diseases with bladder problems has only been descriptive, and few causal mechanisms have been proposed thus far, but these diseases may be candidates for further translational research by the recent OMICS methodology. In contrast, the more common and wellknown cause of refractory daytime incontinence, attention deficit disorder with hyperactivity [23], may be more difficult to analyze, because of the multifactorial and socio-psychological nature of the disease. 
For sporadic $\mathrm{OAB}$ cases, expression level of related molecules, such as prostaglandin E2 and NGF are investigated in clinical samples [9-11].

\section{Nocturnal Enuresis and Diabetes Insipidus}

Nocturnal enuresis, which means involuntary urination during sleep, is experienced by $5 \%-15 \%$ of school children. Bed-wetting is harmful for a child's self-esteem, but fortunately, nocturnal enuresis subsides in most children by adolescence [24,25]. The triad etiology of nocturnal enuresis is nocturnal polyuria, decreased nocturnal bladder capacity, and impaired arousal during sleep by bladder distention. Abnormal diurnal rhythm of plasma vasopressin is reported in patients with enuresis [26], and desmopressin, a synthesized antidiuretic hormone, is now a standard medication for enuretic children showing nocturnal polyuria. Reduction in nocturnal functional bladder capacity is another common feature in pathogenesis of refractory nocturnal enuresis [27]. Impaired arousal during sleep is now treated by alarm therapy.

Although the etiology of nocturnal enuresis is multifactorial, it is probably the most prevalent inherited disease in humans. Since 1995, a Danish group and a Dutch group has reported association of 4 genomic loci with enuresis from analyses of enuretic pedigrees, and named them ENUR1 (13q 13q13-q14.3) [28], ENUR2 (12q) [29], ENUR3 (22p11) [30] and ENUR4 (8q) [31]. However, all likely candidate genes in these loci, like aquaporin or dopamine receptors, have been excluded so far [32]. The pursuit for enuresis genes has been stranded partly because genetic association and enuresis phenotype (bladder or renal type) could not be linked in general [33,34].

Besides these studies in enuretic pedigrees, some groups investigated the polymorphism of candidate genes like 5-hydroxytryptamine receptor $2 \mathrm{~A}$ and nitric oxide synthase in sporadic enuretic patients $[35,36]$.

In rare cases, renal diabetes insipidus (DI) can be a cause of enuresis. Although these are exceptional cases compared to common enuresis cohort, causative molecules like vasopressin 2 receptor (V2R) [37], aquaporin 2 (AQP-2) [38-40], arginine vasopressin-neurophysin II [41], and Wolfram syndrome gene 1 (WFS1) [42] have been identified. Although rare, these cases provide further insights on the pathophysiology and treatment of enuresis. For example, cases of enuresis with DI including those with defective $V 2 R$ or $A Q P$-2 genes, still show positive response to desmopressin, a synthetized vasopressin-like drug, indicating that the desmopressin may have an extrarenal path- way for vasopressin affecting nocturnal enuresis $[40,43,44]$.

Enuretic patients show loss in day-and-night change of urine production from the kidney and functional bladder capacity, but a precise mechanism has not been well-investigated. On the other hand, the recent evolution of molecular chronobiology has demonstrated that several genes in the kidney show circadian oscillation is controlled by the circadian clock, genetic 'machinery' controlling day-and night changes in cellular function. The circadian clock exists in most organs of the body including the kidney, and may contribute to day-and-night change in urine output. Also, our group discovered that the circadian clock exists in the bladder too, and may contribute to day-and-night change in the bladder capacity $[45,46]$. It is highly likely that the circadian clock may play a key role in enuresis, and ideally, reciprocal studies with clinical molecular epidemiology and laboratory biological investigations will clarify the true genetic mechanism of nocturnal enuresis.

\section{Posterior Urethral Valves and Neurogenic Bladder}

Although incontinence and enuresis are highly prevalent conditions, they are not life-threatening. On the other hand, more severe forms of LUTD in children are seen in patients with posterior urethral valves (PUVs) and neurogenic bladder, typically seen in those with congenital spinal disorders. In these diseases, massive fibrosis and remodeling of the bladder smooth muscle is seen, leading to end-stage renal disease if mistreated. The devastating effects of these diseases have attracted the interest of pediatric urologists to the smooth muscle biology, and more specifically, the effect of stretch injury to the bladder smooth muscle cells [47]. However, little extension of these laboratory findings into a clinical context has been done. Genetic or proteomic approach of clinical materials is still scarce in this area, and molecular analysis of clinical end-stage bladder disease occurs only in limited cases like those in which bladder augmentation is indicated. For example, our group performed an immunohistochemical study of the specimen of augmented bladder for parathyroid hormone (PTH) 1 receptor, a receptor of PTH related protein, which is a potent endogenous relaxant of the bladder smooth muscle under distention $[8,48]$.

Recently, a genome-wide study revealed possible association of 47 loci with copy number variants in 32 cases of PUVs [49]. Genetic etiology of neurogenic bladder may belong to neurological investigators. 


\section{Rare Anomalies: Bladder Exstrophy, Cloacal Anomalies, and Others}

Bladder exstrophy and cloacal anomalies are extremely rare, having a profound impact on patients' continence, sexual life, and renal function, requiring complex surgical repair. Since they are major anomalies caused by defective urorectal development, they have recently drawn the attention of basic scientists [50-52]. For bladder exstrophy, a genome-wide association study followed by a whole exome sequencing study revealed the importance of the ISL1-pathway in humans and mice and proposed SLC20A1 and CELSR3 as candidate genes [51,52]. For cloacal anomalies, comparative genomic hybridization revealed CNVs in 7 patients (41\%), including 5 gains and 2 losses [50].

There are much rarer diseases like megacystis microcolon intestinal hypoperistalsis syndrome, which has implicated ACTG2 as a causative gene [53,54]. Investigation of such rare diseases should not be underrated, since the causative genes related to these diseases could also be involved in more common and prevalent conditions.

\section{CONCLUSIONS}

Pediatric bladder diseases might be perceived as 'orphan' diseases, attracting the attention of few clinicians. On the other hand, lower urinary tract symptoms are quite prevalent in elderly patients, represented by $\mathrm{OAB}$ and nocturia. Interestingly, nocturnal enuresis in children and nocturia in the elderly sometimes share the same etiology; increase in nocturnal urine output, decrease in nocturnal bladder volume. In such a sense we may advocate that investigation of genetic etiology of pediatric diseases may elucidate the pathophysiology of a broader range of patients, including adults with LUTD. Since pediatric diseases may have less comorbidity like diabetes mellitus, prostate hypertrophy, and sexual hormonal changes, they may provide researchers opportunities to analyze the effect of genetic alteration per se.

In the interest of pediatric patients themselves, since pediatric LUTD is more likely to be associated with genetic background than is adult LUTD, it may be more suitable for development and application of precision medicine. The reduction of research costs in terms of funding, time, and human effort may hopefully lead to more scientific knowledge that would ultimately contribute to improved health care for pediatric LUTD.

\section{REFERENCES}

1. Lee SD, Sohn DW, Lee JZ, Park NC, Chung MK. An epidemiological study of enuresis in Korean children. BJU Int 2000;85:869-73.

2. Kajiwara M, Inoue K, Kato M, Usui A, Kurihara M, Usui T. Nocturnal enuresis and overactive bladder in children: an epidemiological study. Int J Urol 2006;13:36-41.

3. Atala A, Murphy S. Regenerative medicine. JAMA 2015;313:14134.

4. Kanematsu A, Yamamoto S, Ogawa O. Changing concepts of bladder regeneration. Int J Urol 2007;14:673-8.

5. Fiegler H, Redon R, Andrews D, Scott C, Andrews R, Carder C, et al. Accurate and reliable high-throughput detection of copy number variation in the human genome. Genome Res 2006;16:1566-74.

6. McCarroll SA, Altshuler DM. Copy-number variation and association studies of human disease. Nat Genet 2007;39(7 Suppl):S37-42.

7. Habuka M, Fagerberg L, Hallström BM, Pontén F, Yamamoto T, Uhlen $\mathrm{M}$. The urinary bladder transcriptome and proteome defined by transcriptomics and antibody-based profiling. PLoS One 2015;10:e0145301.

8. Nishikawa N, Yago R, Yamazaki Y, Negoro H, Suzuki M, Imamura $\mathrm{M}$, et al. Expression of parathyroid hormone/parathyroid hormone-related peptide receptor 1 in normal and diseased bladder detrusor muscles: a clinico-pathological study. BMC Urol 2015; $15: 2$.

9. Oktar T, Kocak T, Oner-Iyidogan Y, Erdem S, Seyithanoglu M, Ziylan $\mathrm{O}$, et al. Urinary nerve growth factor in children with overactive bladder: a promising, noninvasive and objective biomarker. J Pediatr Urol 2013;9:617-21.

10. Telli O, Samancı C, Sarıcı H, Hascıcek AM, Kabar M, Eroglu M. Can urinary nerve growth factor and bladder wall thickness correlation in children have a potential role to predict the outcome of non-monosymptomatic nocturnal enuresis? J Pediatr Urol 2015;11: 265.e1-5.

11. Aoki K, Hirayama A, Tanaka N, Yoneda T, Yoshida K, Fujimoto K, et al. A higher level of prostaglandin E2 in the urinary bladder in young boys and boys with lower urinary tract obstruction. Biomed Res 2009;30:343-7.

12. Zürbig P, Jerums G, Hovind P, Macisaac RJ, Mischak H, Nielsen $\mathrm{SE}$, et al. Urinary proteomics for early diagnosis in diabetic nephropathy. Diabetes 2012;61:3304-13.

13. Chen Z, Kim J. Urinary proteomics and metabolomics studies to monitor bladder health and urological diseases. BMC Urol 2016; 16:11.

14. Fouts DE, Pieper R, Szpakowski S, Pohl H, Knoblach S, Suh MJ, et 
al. Integrated next-generation sequencing of $16 \mathrm{~S} \mathrm{rDNA}$ and metaproteomics differentiate the healthy urine microbiome from asymptomatic bacteriuria in neuropathic bladder associated with spinal cord injury. J Transl Med 2012;10:174.

15. Ochoa B, Gorlin RJ. Urofacial (ochoa) syndrome. Am J Med Genet 1987;27:661-7.

16. Tu Y, Yang P, Yang J, Xu Y, Xiong F, Yu Q, et al. Clinical and genetic characteristics for the Urofacial Syndrome (UFS). Int J Clin Exp Pathol 2014;7:1842-8.

17. Wang CY, Hawkins-Lee B, Ochoa B, Walker RD, She JX. Homozygosity and linkage-disequilibrium mapping of the urofacial (Ochoa) syndrome gene to a 1-cM interval on chromosome 10q23-q24. Am J Hum Genet 1997;60:1461-7.

18. Daly SB, Urquhart JE, Hilton E, McKenzie EA, Kammerer RA, Lewis M, et al. Mutations in HPSE2 cause urofacial syndrome. Am J Hum Genet 2010;86:963-9.

19. Stuart HM, Roberts NA, Burgu B, Daly SB, Urquhart JE, Bhaskar S, et al. LRIG2 mutations cause urofacial syndrome. Am J Hum Genet 2013;92:259-64.

20. Niemczyk J, Equit M, Borggrefe-Moussavian S, Curfs L, von Gontard A. Incontinence in persons with Noonan Syndrome. J Pediatr Urol 2015;11:201.e1-5.

21. Backes M, Genç B, Schreck J, Doerfler W, Lehmkuhl G, von Gontard A. Cognitive and behavioral profile of fragile X boys: correlations to molecular data. Am J Med Genet 2000;95:150-6.

22. Kitamura A, Kondoh T, Noguchi M, Hatada T, Tohbu S, Mori K, et al. Assessment of lower urinary tract function in children with Down syndrome. Pediatr Int 2014;56:902-8.

23. Shreeram S, He JP, Kalaydjian A, Brothers S, Merikangas KR. Prevalence of enuresis and its association with attention-deficit/hyperactivity disorder among U.S. children: results from a nationally representative study. J Am Acad Child Adolesc Psychiatry 2009; 48:35-41.

24. Nevéus T. Diagnosis and management of nocturnal enuresis. Curr Opin Pediatr 2009;21:199-202.

25. Robson WL. Clinical practice: evaluation and management of enuresis. N Engl J Med 2009;360:1429-36.

26. Rittig S, Knudsen UB, Nørgaard JP, Pedersen EB, Djurhuus JC. Abnormal diurnal rhythm of plasma vasopressin and urinary output in patients with enuresis. Am J Physiol 1989;256(4 Pt 2):F664-71.

27. Yeung CK, Sit FK, To LK, Chiu HN, Sihoe JD, Lee E, et al. Reduction in nocturnal functional bladder capacity is a common factor in the pathogenesis of refractory nocturnal enuresis. BJU Int 2002; 90:302-7.

28. Eiberg H, Berendt I, Mohr J. Assignment of dominant inherited nocturnal enuresis (ENUR1) to chromosome 13q. Nat Genet 1995; 10:354-6.

29. Arnell H, Hjälmås K, Jägervall M, Läckgren G, Stenberg A, Bengtsson $B$, et al. The genetics of primary nocturnal enuresis: inheritance and suggestion of a second major gene on chromosome 12q. J Med Genet 1997;34:360-5.

30. Eiberg $\mathrm{H}$. Total genome scan analysis in a single extended family for primary nocturnal enuresis: evidence for a new locus (ENUR3) for primary nocturnal enuresis on chromosome 22q11. Eur Urol 1998;33 Suppl 3:34-6.

31. Eiberg H, Shaumburg HL, Von Gontard A, Rittig S. Linkage study of a large Danish 4-generation family with urge incontinence and nocturnal enuresis. J Urol 2001;166:2401-3.

32. von Gontard A, Schaumburg H, Hollmann E, Eiberg H, Rittig S. The genetics of enuresis: a review. J Urol 2001;166:2438-43.

33. Schaumburg HL, Kapilin U, Blåsvaer C, Eiberg H, von Gontard A, Djurhuus JC, et al. Hereditary phenotypes in nocturnal enuresis. BJU Int 2008;102:816-21.

34. Loeys B, Hoebeke P, Raes A, Messiaen L, De Paepe A, Vande Walle J. Does monosymptomatic enuresis exist? A molecular genetic exploration of 32 families with enuresis/incontinence. BJU Int 2002; 90:76-83.

35. Wei CC, Wan L, Lin WY, Tsai FJ. Rs 6313 polymorphism in 5-hydroxytryptamine receptor $2 \mathrm{~A}$ gene association with polysymptomatic primary nocturnal enuresis. J Clin Lab Anal 2010;24:371-5.

36. Balat A, Alasehirli B, Oguzkan S, Gungor M. Nitric oxide synthase gene polymorphisms in children with primary nocturnal enuresis: a preliminary study. Ren Fail 2007;29:79-83.

37. Yamashita S, Hata A, Usui T, Oda H, Hijikata A, Shirai T, et al. Novel AVPR2 mutation causing partial nephrogenic diabetes insipidus in a Japanese family. J Pediatr Endocrinol Metab 2016;29: 591-6.

38. Shalev H, Romanovsky I, Knoers NV, Lupa S, Landau D. Bladder function impairment in aquaporin-2 defective nephrogenic diabetes insipidus. Nephrol Dial Transplant 2004;19:608-13.

39. Bockenhauer D. Draining the edema: a new role for aquaretics? Pediatr Nephrol 2014;29:767-9.

40. Müller D, Marr N, Ankermann T, Eggert P, Deen PM. Desmopressin for nocturnal enuresis in nephrogenic diabetes insipidus. Lancet 2002;359:495-7.

41. Kanemitsu N, Kawauchi A, Nishida M, Tanaka Y, Mizutani Y, Shirahama $S$, et al. Familial central diabetes insipidus detected by nocturnal enuresis. Pediatr Nephrol 2002;17:1063-5.

42. Marshall BA, Permutt MA, Paciorkowski AR, Hoekel J, Karzon R, Wasson J, et al. Phenotypic characteristics of early Wolfram syn- 
drome. Orphanet J Rare Dis 2013;8:64.

43. Robben JH, Sze M, Knoers NV, Eggert P, Deen P, Müller D. Relief of nocturnal enuresis by desmopressin is kidney and vasopressin type 2 receptor independent. J Am Soc Nephrol 2007;18:1534-9.

44. Jonat S, Santer R, Schneppenheim R, Obser T, Eggert P. Effect of DDAVP on nocturnal enuresis in a patient with nephrogenic diabetes insipidus. Arch Dis Child 1999;81:57-9.

45. Negoro H, Kanematsu A, Doi M, Suadicani SO, Matsuo M, Imamura $\mathrm{M}$, et al. Involvement of urinary bladder Connexin 43 and the circadian clock in coordination of diurnal micturition rhythm. Nat Commun 2012;3:809.

46. Negoro H, Kanematsu A, Yoshimura K, Ogawa O. Chronobiology of micturition: putative role of the circadian clock. J Urol 2013;190: 843-9.

47. Halachmi S. The molecular pathways behind bladder stretch injury. J Pediatr Urol 2009;5:13-6.

48. Nishikawa N, Kanematsu A, Negoro H, Imamura M, Sugino Y, Okinami T, et al. PTHrP is endogenous relaxant for spontaneous smooth muscle contraction in urinary bladder of female rat. Endocrinology 2013;154:2058-68.

49. Boghossian NS, Sicko RJ, Kay DM, Rigler SL, Caggana M, Tsai MY, et al. Rare copy number variants implicated in posterior urethral valves. Am J Med Genet A 2016;170:622-33.

50. Harrison SM, Seideman C, Baker LA. DNA copy number variations in patients with persistent cloaca. J Urol 2014;191(5 Suppl): 1543-6.

51. Draaken M, Knapp M, Pennimpede T, Schmidt JM, Ebert AK, Rösch W, et al. Genome-wide association study and meta-analysis identify ISL1 as genome-wide significant susceptibility gene for bladder exstrophy. PLoS Genet 2015;11:e1005024.

52. von Lowtzow C, Hofmann A, Zhang R, Marsch F, Ebert AK, Rösch W, et al. CNV analysis in 169 patients with bladder exstrophy-epispadias complex. BMC Med Genet 2016;17:35.

53. Wangler MF, Gonzaga-Jauregui C, Gambin T, Penney S, Moss T, Chopra A, et al. Heterozygous de novo and inherited mutations in the smooth muscle actin (ACTG2) gene underlie megacystis-microcolon-intestinal hypoperistalsis syndrome. PLoS Genet 2014;10: e1004258.

54. Thorson W, Diaz-Horta O, Foster J 2nd, Spiliopoulos M, Quintero R, Farooq A, et al. De novo ACTG2 mutations cause congenital distended bladder, microcolon, and intestinal hypoperistalsis. Hum Genet 2014;133:737-42. 
Appendix. Summary of the translational research cited in the article

\begin{tabular}{|c|c|c|c|c|c|}
\hline Disease & Reference & Year & Category & Methodology & Molecules and findings \\
\hline \multicolumn{6}{|l|}{ Incontinence/OAB } \\
\hline \multirow[t]{4}{*}{ Urofacial syndrone } & Ochoa [15] & 1987 & Clinical Study & Clinical Study & $\mathrm{N} / \mathrm{A}$ \\
\hline & Wang [17] & 1997 & Genetic locus & Genome mapping & $10 \mathrm{q} 23-\mathrm{q} 24$ \\
\hline & Daly [18] & 2010 & Genomic mutation & Genome mapping & HPSE2 (heparanase-2) \\
\hline & Stuart [19] & 2014 & Bialleric mutation & Genetic sequencing & LRIG2 \\
\hline \multirow[t]{3}{*}{ Sporadic OAB } & Aoki [11] & 2009 & Urinary Eicosanoid & ELISA & Prostaglandin E2 \\
\hline & Oktar [9] & 2013 & Urinary protein & ELISA & Nerve growth factor \\
\hline & Telli [10] & 2015 & Urinary protein & ELISA & Nerve growth factor \\
\hline \multicolumn{6}{|l|}{ Nocturnal enuresis } \\
\hline \multirow[t]{5}{*}{ Familial enuresis } & Eiberg [28] & 1995 & Genetic locus & Genome mapping & 13q13-q14.3 (ENUR1) \\
\hline & Amell [29] & 1997 & Genetic locus & Genome mapping & 12q ( ENUR2) \\
\hline & Eiberg [30] & 1998 & Genetic locus & Genome mapping & 22q11 (ENUR3) \\
\hline & Eiberg [31] & 2001 & Genetic locus & Genome mapping & 4p16.1(ENUR4) \\
\hline & Loeys [34] & 2002 & Genetic locus & Genome mapping & $22 \mathrm{q} 11,13 \mathrm{q} 13-14,12 \mathrm{q}$ \\
\hline \multirow[t]{2}{*}{ Soradic enuresis } & Wei [35] & 2010 & Polymorophism & PCR-RFLP & 5-hydroxytryptamine receptor $2 \mathrm{~A}$ gene \\
\hline & Balat [36] & 2007 & Polymorophism & PCR-RFLP & Nitric oxide synthase gene polymorphisms \\
\hline \multirow[t]{6}{*}{ Diabetus insipidus } & Müller [40] & 2002 & Genetic mutation & Targeted sequencing & Aquaporin-2 gene \\
\hline & Kanemitsu [41] & 2002 & Genetic mutation & Targeted sequencing & Arginine vasopressin-neurophysin II \\
\hline & Shalev [38] & 2004 & Genetic mutation & Targeted sequencing & Aquaporin-2 \\
\hline & Robben [43] & 2007 & Genetic mutation & Targeted sequencing & $V 2 R$ gene deficiency \\
\hline & Marshall [42] & 2013 & Clinical Study & Clinical Study & WFS1 gene, encoding wolframin \\
\hline & Yamashita [37] & 2016 & Genetic mutation & Targeted sequencing & $V 2 R$ gene deficiency in partial DI \\
\hline Posterior urethral valve & Boghossian [49] & 2016 & DNA CNV & WGS & 47 rare candidate CNVs in 32 cases \\
\hline Neurogenic bladder & Nishikawa [8] & 2015 & Protein & Immunostaining & PTH-PTH related protein receptor 1 \\
\hline \multirow[t]{2}{*}{ Exstrophy } & Draaken [51] & 2015 & Genetic mutation & GWAS & ISL1 \\
\hline & von Lowtzow [52] & 2016 & DNA CNV & WGS & Rare CNVs identified \\
\hline Cloaca & Harrison [50] & 2014 & DNA CNV & WGS & $\mathrm{CNV}$ in $41 \%$ of caese, 5 gain and 2 loss \\
\hline \multirow[t]{2}{*}{ MMHIS } & Wangler [53] & 2014 & Genetic mutation & WGS & ACTG2 gene missense variants \\
\hline & Thorson [54] & 2014 & Genetic mutation & WGS & ACTG2 gene mutation \\
\hline
\end{tabular}

OAB, overactive bladder; N/A, not applicable; ELISA, enzyme-linked immunosorbent assay; PCR-RFLP, polymerase chain reaction-restriction fragment length polymorphism; DNA CNV, DNA copy number variant; DI, diabetes insipidus; WGS, whole genome sequencing; GWAS, genome-wide association study; MMHIS, megacystis microcolon intestinal hypoperistalsis. 